\title{
Application of Analytic Hierarchy Process in Quality Function Deployment For Improving Quality at Industrial Engineering Department University " $X$ "
}

\author{
Hendry Raharjo \\ Dian Retno Sari Dewi \\ Industrial Engineering, Widya Mandala Catholic University \\ Jl. Kalijudan 37 Surabaya, Indonesia. Phone. (+62-31) 3891264, Fax.(+62-31) 3891267 \\ hendry@mail.wima.ac.id
}

Keywords: QFD, AHP, Internal Customer, External Customer, Sensitivity Analysis

\section{Summary}

Quality Function Deployment (QFD) is an alternative to recognize/ listen to the Voice Of Customer (VOC) better in manufacturing industry as well as in service industry. This paper describes QFD implementation in translating the VOC to improve quality at an industrial engineering department of a university in Indonesia. The customers are divided into two major categories, the internal customer, which consists of the lecturers and the students; and the external customer, which is employers of the graduates. Knowledgeable decision makers that are representative to each of the parties assist the completion of the weighting process of the customer requirements' importance rating. After completing the QFD chart, it can be revealed what the primary priorities are in order to design strategies to improve quality at the industrial engineering department.

As an initial phase, three parties, which are the lecturers, the students, and the employers, are interviewed on one-on-one basis. This phase is aided by affinity diagram for Demanded Quality's classification purpose. Afterwards, each Demanded Quality is explored hierarchically by tree diagram and translated into appropriate Quality Characteristic. To assign priorities/ level of importance of the Demanded Quality, questionnaires using AHP's pairwise comparisons are provided for five representative decision makers. The questionnaires are then processed with Expert Choice software to measure the weight of the Demanded Quality as well as to check the consistency of the decision makers. Finally, the House of Quality of each customer is constructed using Ms-Excel software to proceed with QFD analysis. QFD matrices are fulfilled by representative department team and verified using the HOQ check proposed by Ohfuji and Nakui (Akao Prize, 1998).

HOQ (House Of Quality) is the central/ basic tool in constructing QFD. A schematic of a HOQ chart is shown in Figure 1.

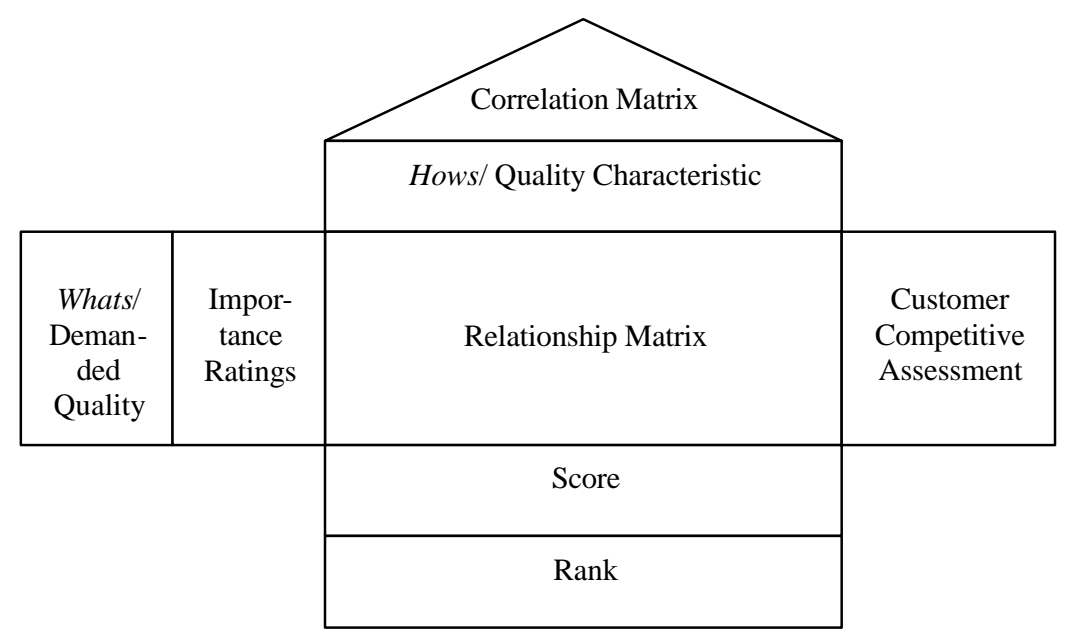

Figure 1. Basic Model of House Of Quality (HOQ) 
In the QFD matrix, AHP is used particularly to fill the left west wing part of the HOQ that is the Importance Ratings (refer to Fig.1). AHP technique uses pairwise comparisons, which are the most accurate way to elicit relative priorities of a set of objects. With regard to inconsistency of human mind, the AHP's pairwise judgments procedure and its powerful philosophy of it is better to be approximately right than precisely wrong lead to a limit of $10 \%$ inconsistency level (Peniwati, 2000). The weight of each DQ is calculated through pairwise comparison questionnaires given to every decision maker. Due to the large number of DQ, the comparisons will be very tedious. Therefore, clustering is employed to reduce the number of comparisons. Afterwards, a reciprocal matrix is constructed to evaluate the consistency level. Consistency level is checked using Expert Choice software, however, if the consistency level goes beyond $10 \%$, resurvey is conducted to each of the decision makers.

From each of the QFD matrices analysis, the customers' requirements can be sorted out in the order of importance so that it can be known what matters most to each customer. Alternative solution to the department can be derived from the scores/ ranks of the Quality Characteristics. Primary alternative solutions for each of the customer can be compressed as: for the students' party, to provide development funds from the university, conduct more comparative study and market needs' survey, obtain feedback from employers, and intensify internship and project at industries. For the lecturers' party, to explain the procedure of obtaining funds, divide big classes into smaller ones as well as to determine the policy regarding the maximum/ minimum number of students per class, and purchase high quality and relevant books. For the employers' party, to give more team assignment and leadership training, get involved in committee activities, and intensify discussion and presentation.

Based on gap analysis t-test to check the significant distance between the existing and expected condition of the customer requirements, it is concluded that most of the requirements have significant gap, except for lecturers' working atmosphere, students' campus location and extracurricular.

Sensitivity analysis is conducted in order to anticipate future changes of customers' interest and to investigate the most sensitive component of the DQ. The effect of changing the DQ in the sensitivity analysis has given insight into the alteration of the QC's priority. For the students' party, the DQs that induce highest volatility in rank, consecutively, are facility, lecturer, extracurricular, administration, location, external relationship and curriculum. For lecturers' party, the DQs, in order from the most sensitive one, are facility, working environment, curriculum and bureaucracy. While for employers' party, the DQs that cause highest instability in rank, consecutively, are academic qualification, problem solving skill, interpersonal skill and leadership skill.

In brief, endeavors that the concerning department should take as a main priority are to develop overall facility, reevaluate existing curriculum, reduce unnecessary bureaucracy, improve lecturers' qualification and provide more leadership/ team training. Alternative solutions that are generated from the QFD depend fully on level of importance of the customer requirements. Any changes in the Demanded Quality's level of importance will alter the order of alternative solutions. The HOQ should be adjusted and updated when there are some changes in the existing condition, and it is very possible to add more relevant Quality Characteristics to the HOQ. 